\title{
EDITORIAL
}

\section{Bronchiectasis: why the diagnosis shouldn't be missed in primary care}

See linked article by Hill et al.

on pg 135

\section{*Charles Feldman ${ }^{a}$}

a Professor of Pulmonology and Chief Physician, Charlotte Maxeke Johannesburg Academic Hospital and University of the Witwatersrand, Johannesburg, South Africa

*Correspondence:

Professor Charles Feldman

Division of Pulmonology,

Department of Internal Medicine,

Faculty of Health Sciences,

University of the Witwatersrand,

7 York Road, Parktown, 2913,

Johannesburg,

South Africa

Tel: +27 11 488-3840

Fax: + $2711488-4675$

E-mail: charles.feldman@wits.ac.za

Commissioned article

Not externally peer-reviewed

Accepted 19th April 2011

Online 20th May 2011
Bronchiectasis unrelated to cystic fibrosis has been called an "orphan disease" and a "much neglected disease", having had a low profile until very recently. ${ }^{1-3}$ Part of the reason for this is the impression that the condition is uncommonly seen and is therefore of decreasing importance - particularly in the developed world - mainly as a consequence of childhood vaccination and the effective use of antibiotics for the management of respiratory tract infections. However, since the advent of high resolution CT (HRCT) scanning of the chest, the diagnosis of bronchiectasis is being made with increasing frequency throughout the world and the condition has become recognised as an important and common cause of respiratory disease. ${ }^{2-5}$

Bronchiectasis is important to recognise since it may cause severe and recurrent pulmonary infections, with associated permanent and progressive loss of lung function leading to significant morbidity and even premature mortality. ${ }^{1}$ For example, a recent mortality study conducted in England and Wales reported the number of deaths from bronchiectasis to be increasing by $3 \%$ per annum in the older age groups, and this despite likely underreporting - thus necessitating increased clinical provision for these patients to reverse this trend. ${ }^{6}$ Frequent exacerbations and/or delayed treatment are clearly associated with lung function decline - itself a mortality risk - whereas there is considerable and increasing evidence that progression of airway damage can be limited with intensive medical treatment even in patients who are predestined to have bronchiectasis, such as those with immune deficiency. Furthermore, in some children with bronchiectasis, resolution or considerable improvement of the changes seen on HRCT scanning of the chest have been noted, underlining the importance of early diagnosis and treatment of the condition. ${ }^{5.7}$ It is for these reasons that early diagnosis and institution of appropriate care are essential.

Therefore, it is pleasing to note the resurgence of interest in this condition culminating in the development of bronchiectasis management guidelines - one of which ${ }^{8}$ has been highlighted with a primary care summary in this issue of the $P C R J .{ }^{9}$ The first step in primary care is to recognise that an individual patient may have bronchiectasis and that one needs to confirm the diagnosis. ${ }^{9}$ Although symptoms are very non-specific, the diagnosis should always be suspected in an individual presenting with cough productive of sputum, and/or unexplained haemoptysis. ${ }^{1-4}$ The diagnosis should also be considered in children with "asthma" that responds poorly to treatment, and similarly in adults with "chronic obstructive pulmonary disease (COPD)" $2.4,5,9$ The plain chest X-ray - which is recommended for all patients - is not sufficiently sensitive for adequate diagnosis of the condition, and the use of bronchography has been replaced by HRCT scanning of the chest, which is currently considered the gold standard for bronchiectasis diagnosis. ${ }^{12}{ }^{1}$ It is the more widespread use of HRCT scanning that has largely contributed to the recognition of the importance of bronchiectasis.

Once a diagnosis is made, most patients (and especially the problematic ones) will require referral to secondary care for further assessment and evaluation for an underlying cause. ${ }^{911}$ Importantly, in both children and adults it has been conclusively shown that investigating patients with bronchiectasis for an underlying cause is very important since this leads to the identification of a treatable condition in more cases than was previously thought - leading to an alteration in therapy to target these conditions - and this can have significant prognostic implications. ${ }^{4,11-13}$ 


\section{Feldman}

Whilst there are a myriad of treatment options potentially available for the management of patients with bronchiectasis, few have been appropriately studied in randomised controlled trials; many treatment recommendations are based either on guidelines for the management of cystic fibrosis, or extrapolation from the management of other respiratory conditions, or even purely expert opinion. 2,14,15 The general aims of treatment are to limit the cycle of infection and inflammation in order to halt the progression of airway damage, to reduce symptoms and the number of exacerbations, and to improve quality of life. ${ }^{1,7}$ The natural history of bronchiectasis and its associated mortality can be improved with expert management, with increasing evidence that early and intensive treatment can improve lung function in children and prevent deterioration, reduce respiratory exacerbations, and improve the overall long-term prognosis. ${ }^{7}$ Primary care plays an important overall role in patient management, which should include comprehensive education for the patient about the condition and its treatment, as well as ongoing patient assessment, monitoring of therapy, and further referral to secondary care in specific circumstances. ${ }^{9}$ The primary care guideline summary by Hill et al. ${ }^{9}$ gives clear indications regarding the appropriate assessment and treatment of patients with bronchiectasis, while identifying the many areas that require further research in order to clarify the issues. ${ }^{8}$

It is hoped that a guideline such as this ${ }^{8,9}$ will not only increase the awareness of the importance of bronchiectasis, but also lead to improved management in the hope of decreasing its considerable morbidity.

\section{Conflict of interests}

The author has nothing to disclose.

\section{References}

1. O'Donnell AE. Bronchiectasis. Chest 2008;134:815-23. http://dx.doi.org/ 10.1378/chest.08-0776

2. Stafler P, Carr SB. Non-cystic fibrosis bronchiectasis: its diagnosis and management. Arch Dis Child EduC Pract Ed 2010;95:73-82. http://dx.doi.org/10.1136/adc.2007.130054
3. King PT, Daviskas E. Pathogenesis and diagnosis of bronchiectasis. Breathe 2010;6:343-51. http://dx.doi.org/10.1183/18106838.0604.342

4. Smith VM, Shoemark A, Nisbet M, Wilson R. When to think of bronchiectasis and the investigations to perform. Clin Pulm Med 2010;7:7-13. http://dx.doi.org/10.1097/CPM.0b013e3181c84a71

5. Al Subie H, Fitzgerald DA. Non-cystic fibrosis bronchiectasis. Journal of Paediatrics and Child Health 2010;Oct 6. [E-pub ahead of print].

6. Roberts HJ, Hubbard R. Trends in bronchiectasis mortality in England and Wales. Resp Med 2010;104:981-5. http://dx.doi.org/10.1016/j.rmed.2010.02.022

7. Chang $A B$, Byrnes CA, Evwerard ML. Diagnosing and preventing chronic suppurative lung disease (CSLD) and bronchiectasis. Paediatr Respir Rev 2011; 12:97-103. http://dx.doi.org/10.1016/j.prrv.2010.10.008

8. Pasteur MC, Bilton D, Hill AT on behalf of the British Thoracic Society Bronchiectasis (non-CF) Guideline Group: a sub-group of the British Thoracic Society Standards of Care Committee. Guideline for non-CF bronchiectasis. Thorax 2010;65:i1-158. http://dx.doi.org/10.1136/thx.2010.136119

9. Hill AT, Pasteur MC, Cornford C, Welham S, Bilton D. Primary care summary of the British Thoracic Society Guideline on the management of non-cystic fibrosis bronchiectasis. Prim Care Respir J 2011;20(2):135-40. http://dx.doi.org/ 10.4104/pcrj.2011.00007

10. Wilson R. Bronchiectasis. In: Niederman MS, Sarosi G, Glassroth J (eds). Respiratory Infections (2nd edition). Philadelphia: Lippincott Williams and Wilkins, 2001:347 - 359 .

11. Shoemark A, Ozerovitch L, Wilson R. Aetiology in adult patients with bronchiectasis. Resp Med 2007;101:1163-70. http://dx.doi.org/10.1016/ j.rmed.2006.11.008

12. Zoumot $Z$, Wilson R. Respiratory infection in noncystic fibrosis bronchiectasis. Curr Opin Infect Dis 2010;23:165-70. http://dx.doi.org/10.1097/ QC0.0b013e328335af91

13. Li AM, Sonnappa S, Lex C, et al. Non-CF bronchiectasis: does knowing the aetiology lead to changes in management? Eur Respir J 2005;26:8-14. http://dx.doi.org/10.1183/09031936.05.00127704

14. Tsang KW, Bilton D. Clinical challenges in managing bronchiectasis. Respirology 2009;14:637-50. http://dx.doi.org/10.1111/j.1440-1843.2009. 01569.x

15. Metersky ML. New treatment options for bronchiectasis. Ther Adv Respir Dis 2010;4:93-9. http://dx.doi.org/10.1177/1753465810366858

\section{Editors' note}

The PCRS-UK has also published an Opinion sheet on the management of bronchiectasis. See www.pcrs-uk.org/opinions/ OS41_bronchiectasis.pdf

Available online at http://www.thepcrj.org 